\title{
For-profit versus not-for-profit delivery of long-term care
}

\author{
Kimberlyn M. McGrail, Margaret J. McGregor, Marcy Cohen, Robert B. Tate, Lisa A. Ronald
}

$\mathrm{P}$ ublic funds can be used to pay for health care services that are delivered either by for-profit or not-for profit agencies. A systematic review of patient outcomes in US hospitals by ownership status showed that not-for-profit hospitals tended to produce better results. ${ }^{1}$ Although there are no Canadian acute care hospitals in the for-profit sector, the issue of interest here is whether the same trend in outcomes applies to for-profit and not-for-profit ownership of long-term care facilities.

About $60 \%$ and $30 \%$ of all publicly funded long-term care beds in Ontario and British Columbia, respectively, are in forprofit institutions. ${ }^{2,3}$ The co-existence of for-profit and notfor-profit providers in the same province creates a "natural laboratory" for examining their differences. This is particularly true because the funding paid by the province to these facilities is tied to resident care requirements and thus the same amount is paid per standardized patient whether he or she is in a for-profit or a not-for-profit facility. Despite this, there has been relatively little Canadian research that examines the experiences of residents in these 2 types of facilities. Although there is an abundance of evidence from the United States demonstrating superior performance of the not-forprofit sector in measures of quality of care, there are claims that these findings have limited generalizability in Canada because of differences in the 2 countries' health care systems. However, a few Canadian studies are now starting to provide a portrait of what public investment "buys" in for-profit and not-for-profit facilities.

\section{How is the money spent?}

Long-term care facilities, like hospitals, are labour-intensive; therefore, staffing costs account for a significant portion of total expenditures. Unlike many parts of the United States, Canada has no legislated minimal requirements for staffing in longterm care facilities. Instead, institutions either face requirements for minimum spending in different categories as dictated by "funding envelopes" (as in Ontario), or are free to choose how to apportion their funding (as in British Columbia).

There is now increasing evidence that the for-profit and not-for-profit sectors in Canada make different spending decisions. In an Ontario study, government-operated facilities were found to provide more hours of direct patient care per resident than for-profit facilities, although the public-sector facilities also care for residents with greater health needs. ${ }^{2}$ In British Columbia, not-for-profit facilities were also found to provide more hours of direct patient care per resident than for-profit facilities, with the same funding level from government; this difference remained after adjustment for the size and level of care of the facilities. ${ }^{3}$ Adjustment for the mix of patients cared for by the 2 types of facilities is important. For example, most extended-care beds, reserved for the care of the frailest elderly patients, are in not-for-profit facilities.

\section{What are the outcomes of care?}

Do differences in staffing levels result in differences in care? Two studies in Canada have identified a link between ownership type and care outcomes. Although this was not the primary question under study, Shapiro and Tate ${ }^{4}$ found that, in Manitoba, for-profit long-term care facilities had higher rates of acute care hospital admission of residents because of several quality-of-care related diagnoses than did not-forprofit facilities.

In another study, the influence of ownership on patient outcomes was addressed directly with the use of data from the late I99os in British Columbia. ${ }^{5}$ This study compared hospital admission rates for 6 care-sensitive diagnoses among British Columbia residents in for-profit and not-for-profit long-term care facilities. Rates of admission because of anemia, pneumonia and dehydration were found to be higher in for-profit facilities than in their not-for-profit counterparts, after adjustment for resident case mix and other potential confounders. The aggregated superiority of the not-for-profit sector was largely driven by not-for-profit facilities that were attached to acute care hospitals, were amalgamated to a health authority or had more than one site. In the case of not-for-profit single-site facilities, hospital admission rates were the same as, and for 2 diagnoses were higher than, rates in for-profit facilities. The variation of performance among not-for-profit facilities with different organizational characteristics was not replicated in the for-profit sector. Hospital admission rates for all for-profit groups chain, multi-site and single-site - were uniform and higher.

\section{Why the difference in performance?}

One possible explanation for the improved outcomes observed in the not-for-profit long-term care facilities that were attached to acute care hospitals, were amalgamated to a health authority, or were multi-site facilities is that these institutions are able to benefit from the economies of scale afforded by their connection to larger administrative structures. They may, for example, have greater access to specialized professionals capable of developing and implementing care policies. Larger groupings of public facilities may also promote the sharing of clinical services that would be too expensive to operate at a single site. For example, a single clinical or geriatric nurse specialist might be shared among several sites. In addition, facilities attached to acute care hospitals likely have direct access to general, specialty and diagnostic services that may well im- 
prove care outcomes. Whatever the reason, however, any possible advantage of larger administrative groupings does not appear to extend to for-profit facilities.

Differences in staffing between for-profit and not-for-profit long-term care facilities are not surprising. Given the same level of funding, for-profit facilities must, by definition, divert some of their funding to profits. Since staff costs account for a large portion of total budget expenditures, this is a natural place to try to realize cost savings. The fact that differences in spending decisions appear to result in better care outcomes, at least in larger affiliated not-for-profit facilities, is important information for future policy decisions. Further study is necessary, however, because all of these variables have not yet been analyzed together in a Canadian study, and because we need a better understanding of the reasons for the substantial differences in patient outcomes among the different types of not-for-profit facilities.

Nevertheless, we are beginning to acquire evidence from Canadian data that public investment in not-for-profit, rather than for-profit, delivery of long-term care results in more staffing and improved care outcomes for residents. This information is essential to planners as they make funding decisions about long-term care.

This article has been peer reviewed.

Kimberlyn McGrail is with the Centre for Health Services and Policy Research, University of British Columbia, Vancouver, BC; Margaret McGregor and Lisa Ronald are with the Department of Family Practice, University of
British Columbia and the Centre for Clinical Epidemiology and Evaluation, Vancouver Coastal Research Institute, Vancouver, BC; Marcy Cohen is with the Hospital Employees' Union, Vancouver, BC; and Robert Tate is with the Department of Community Health Sciences, University of Manitoba, Winnipeg, Man

Competing interests: None declared.

Contributors: Kimberlyn McGrail was responsible for drafting the commentary. All of the authors contributed substantially to the concept and design of the commentary, revised it critically for important intellectual content and gave final approval of the version to be published.

\section{REFERENCES}

I. Devereaux PJ, Choi PT, Lacchetti C, Weaver B, Schunemann HJ, Haines T, et al. A systematic review and meta-analysis of studies comparing mortality rates of private for-profit and private not-for-profit hospitals. $C M A J$ 2002;166:1399-406.

2. Berta W, LaPorte A, Valdemanis V. Observations on institutional long-term care in Ontario: 1996-2002. Can J Aging 2005;24:70-84.

3. McGregor MJ, Cohen M, McGrail KM, et al. Staffing levels in not-for-profit and forprofit long-term care facilities: Does type of ownership matter? CMAJ 2005;172:645-9.

4. Shapiro E, Tate RB. Monitoring the outcomes of quality of care in nursing homes using administrative data. Can J Aging I995;I4:755-68.

5. McGregor MJ, Tate RB, McGrail KM, et al. Care outcomes in long-term care facilities in British Columbia, Canada: Does ownership matter? Med Care 2006;44:929-35.

Correspondence to: Dr. Kimberlyn McGrail, Centre for Health Services and Policy Research, University of British Columbia, 20I-2206 East Mall, Vancouver BC V6T IZ3; fax 604 822-569o; kmcgrail@chspr.ubc.ca
The complete picture on research.

RRAGTCNL REERAIT. CNAJ E HOW

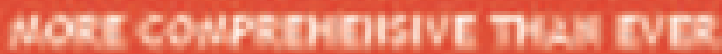

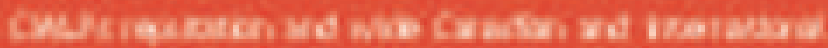

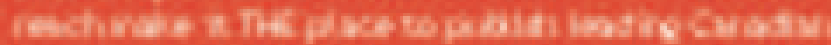

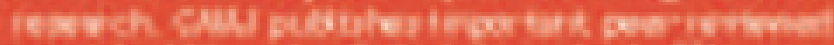

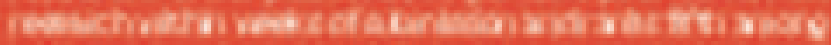

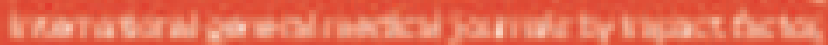

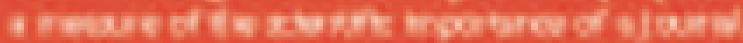

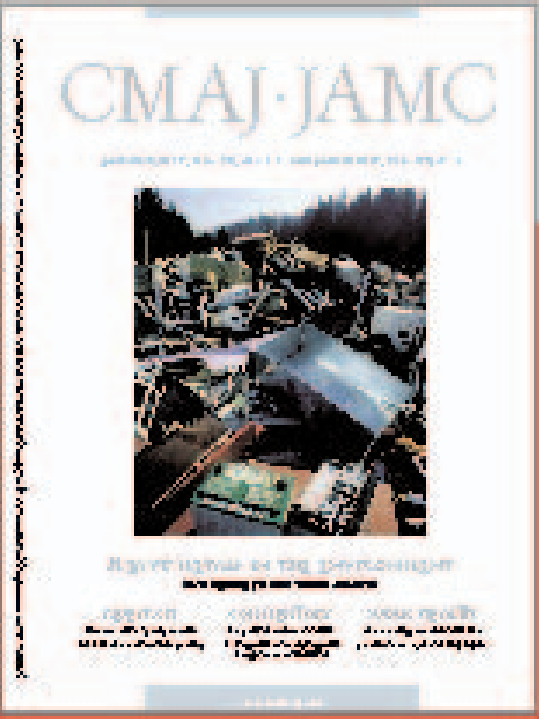

The exsential mear. 